\title{
PERBANDINGAN KADAR MIKROALBUMINURIA PADA STROKE INFARK ATEROTROMBOTIK DENGAN FAKTOR RISIKO HIPERTENSI DAN PASIEN HIPERTENSI
}

\author{
SA Putri, Nurdjaman Nurimaba, Henny Anggraini Sadeli, Thamrin Syamsudin \\ Bagian Ilmu Penyakit Saraf \\ Fakultas Kedeokteran Universitas Padjadjaran/Rumah Sakit Hasan Sadikin Bandung
}

\begin{abstract}
ABSTRAK
Mikroalbuminuria berhubungan dengan kerusakan vaskular di sistem glomerular ginjal yang disebabkan oleh faktorfaktor risiko vaskular antara lain: tekanan darah tinggi, diabetes melitus, profil lipid, merokok, usia lanjut, faktor genetika, dan proses aterosklerosis. Mikroalbuminuria juga menggambarkan kerusakan vaskular di tempat lain termasuk di serebral. Hubungan mikroalbuminuria dengan penyakit serebrovaskular belum banyak diketahui. Penelitian ini merupakan penelitian kasus kontrol dengan pendekatan analitik observasional yang dilakukan di Rumah Sakit Hasan Sadikin Bandung periode Desember 2007-Juli 2008. Pemeriksaan mikroalbuminuria dilakukan pada kelompok kasus (35 subjek stroke infark aterotrombotik dengan faktor risiko hipertensi saja) dan kelompok kontrol (35 subjek dengan hipertensi). Perbandingan kadar mikroalbuminuria antara kedua kelompok dianalisis dengan uji T Independen. Sementara untuk faktor penentu kejadian stroke digunakan uji regresi logistik multipel. Rata-rata kadar miroalbuminuria pada kelompok kasus lebih tinggi (54,76 mg/24 jam) dibanding kelompok kontrol $(23,56 \mathrm{mg} / 24 \mathrm{jam})$ dengan perbedaan yang bermakna $(p=0,013)$. Hasil analisis regresi logistik multipel menunjukkan miroalbuminuria merupakan faktor penanda independen kejadian stroke infark aterotrombotik pada pasien dengan faktor risiko hipertensi $(p=0,032 ; O R=2,91 ; C 195 \%)$. Pasien hipertensi dengan mikroalbuminuria memiliki potensi terjadinya stroke infark aterotrombotik 2,91 kali dibandingkan pasien hipertensi tanpa mikroalbuminuria. Disarankan pemeriksaan mikroalbuminuria sebagai pemeriksaan rutin pada pasien hipertensi untuk preventif primer stroke infark aterotrombotik.
\end{abstract}

Kata kunci: Stroke infark aterotrombotik, faktor risiko hipertensi, mikroalbuminuria

\section{COMPARISON OF MICROALBUMINURIA LEVEL BETWEEN ATHEROTROMBOTIC INFARCTION STROKE WITH HYPERTENSION RISK FACTOR AND PATIENT WITH HYPERTENSION}

\begin{abstract}
Microalbuminuria is a marker of vascular damage in glomerular system caused by vascular risk factors : hypertension, diabetes mellitus, lipid profile, smoking, older age, genetic and atherosclerosis. Microalbuminuria is a window of vasculature damage in cerebrovascular system. Correlation between microalbuminuria and cerebrovascular disease is not well established. This was an observational analytical case control study, conducted on December 2007 to July 2008 in Hasan Sadikin Hospital Bandung. Measurement of microalbuminuria level was done in case group (35 subjects atherotrombotic infarction stroke with hypertension as the risk factor) and control group (35 subjects with hypertension). Comparison of microalbuminuria level were analyzed with independent $T$ test. Determinant factor for atherotrombotic infarction stroke incidence was analyzed with multiple regression logistic. Mean rate of microalbuminuria level in case group was higher ( $54.76 \mathrm{mg} / 24$ hours) compared with control (23.56 $\mathrm{mg} / 24$ hours) and comparison was significant $(\mathrm{p}=0.013)$. Multiple logistic regression analyzed that microalbuminuria as an independent determinant factor for atherotrombotic infarction stroke in patients with hypertension $(p=0.032$, $\mathrm{OR}=2.91$, Cl95\%). Patients with hypertension and microalbuminuria had an increased risk for atherotrombotic infarction stroke 2,91 times than hypertension without microalbuminuria. Microalbuminuria level suggested as a routine examination in patients with hypertension for primary prevention of atherotrombotic infarction stroke.
\end{abstract}

Key words: Atherotrombotic infarction stroke, hypertension, microalbuminuria

Alamat Korespondensi:

dr. S.A. Putri

Bagian IImu Pengyakit SarafFakultas Kedokteran Unpad/

Rumah Sakit Hasan Sadikin Bandung

Jl. Pasteur No.38 Bandung 40161

Telp/Fax 022-203698, HP 081808558428

Email poetri_neu@yahoo.com 


\section{PENDAHULUAN}

Penelitian mengenai mikroalbuminuria baik dari aspek sebagai petanda (marker) adanya suatu penyakit maupun sebagai faktor penentu atau petanda risiko (risk marker) timbulnya suatu penyakit bahkan progresivitas penyakit tersebut telah banyak dilakukan. Hipotesis STENO, the kidney is a window of the vasculature, yang dikemukakan oleh Deckert dkk., ${ }^{1}$ menyimpulkan bahwa bocornya albumin kedalam urin merupakan refleksi kerusakan vaskular menyeluruh di luar ginjal. Dari penelitian tentang mikroalbuminuria, didapatkan bahwa tekanan darah sistolik maupun diastolik yang meningkat, hiperglikemia dan lamanya seseorang menderita diabetes melitus, profil lipid, merokok, usia lanjut, bahkan juga faktor genetika merupakan faktor yang mempengaruhi progresivitas terjadinya mikroalbuminuria. Hal ini mengindikasikan adanya hubungan mikroalbuminuria dengan beberapa faktor risiko vaskular seperti hipertensi, usia lanjut, jenis kelamin, diabetes melitus, merokok, obesitas, dan dislipidemia, serta penyakit akibat faktor risiko vaskular tersebut seperti penyakit stroke. Patogenesis yang mendasarinya adalah proses aterosklerotik. ${ }^{2-4}$ Selain itu ada hubungan bermakna antara tebalnya kompleks intima media arteri karotis yang mencerminkan progresivitas terbentuknya aterosklerosis pada pembuluh darah ini dan mikroalbuminuria. Beberapa penelitian besar mikroalbuminuria hubungannya dengan stroke, telah membuka pemikiran akan pentingnya menggali peran mikroalbuminuria terhadap morbiditas dan mortalitas stroke. ${ }^{1,2,5}$ Telah dilaporkan sebanyak $69 \%$ pasien mikroalbuminuria meninggal dalam 10 tahun; 58\% kematian akibat kardiovaskular dan serebrovaskular, $7 \%$ akibat end state renal disease (ESRD). ${ }^{2,6}$ Hal terpenting adalah mikroalbuminuria dapat menjadi tolok ukur progresivitas penyakit dan prognosisnya di kemudian hari.

Di Indonesia kasus stroke merupakan kasus terbanyak di bangsal rawat inap bagian saraf berdasarkan data statistik periode Januari hingga Desember 2006 dengan faktor risiko terutama hipertensi. ${ }^{7}$ Terlebih lagi stroke merupakan faktor risiko kematian nomor dua tertinggi setelah penyakit kardiovaskular. ${ }^{8}$ Berawal dari kenyataan tersebut, penelitian yang dilakukan ini ingin lebih menggali hubungan mikroalbuminuria dengan stroke, khususnya stroke infark aterotrombotik pada pasien hipertensi. Apakah terdapat perbedaan kadar mikroalbuminuria antara pasien hipertensi yang menderita stroke infark aterotrombotik dan pasien hipertensi yang tidak menderita stroke infark aterotrombotik? Bila terdapat perbedaan, diduga pasien hipertensi yang mempunyai mikroalbuminuria berarti risikonya terhadap kejadian stroke infark aterotrombotik lebih tinggi dibandingkan pasien hipertensi tanpa mikroalbuminuria. Hasil penelitian ini diharapkan mikroalbuminuria dapat menjadi tolok ukur evaluasi penatalaksanaan faktor risiko hipertensi sebagai tindakan preventif primer (primary prevention) terhadap kejadian stroke infark aterotrombotik.

\section{METODE}

Penelitian ini merupakan penelitian uji korelasi dengan pendekatan observasional menggunakan rancangan kasus kontrol. Subjek penelitian yaitu pasien hipertensi yang menderita stroke infark aterotrombotik kejadian pertama kali, dirawat di Rumah Sakit Hasan Sadikin (RSHS) Bandung periode Desember 2007-Agustus 2008. Sebagai subjek kontrol adalah pasien hipertensi yang tidak menderita stroke yang berobat di RSHS atau berada di lingkungan RSHS (pasien rawat inap maupun rawat jalan, tenaga medis, paramedis, ataupun nonmedis). Pengumpulan sampel adalah secara konsekutif dengan besar sampel sebanyak 70 orang. Setiap subjek penelitian dilakukan pengumpulan data meliputi: usia, jenis kelamin, hasil laboratorium yang diperlukan, EKG, foto toraks, dan CT scan kepala (hanya untuk kelompok kasus). Kemudian dilakukan pengambilan urin sewaktu pagi hari dan dikirim ke satu laboratorium yang telah ditunjuk untuk pemeriksaan mikroalbuminuria.

Analisis statistik yang digunakan pada penelitian ini adalah uji statistik $\mathrm{T}$ independen untuk melihat kemaknaan perbedaan kadar mikroalbuminuria pada pasien stroke infark aterotrombotik faktor risiko hipertensi dengan pasien hipertensi tanpa stroke. Sementara untuk menilai besarnya pengaruh tersebut digunakan analisis multivariat dengan perhitungan rasio kecenderungan atau Ratio Odd (OR).

\section{HASIL}

Subjek penelitian pada kelompok kasus, yaitu pasien hipertensi yang menderita stroke infark aterotrombotik, terdiri dari 20 orang laki-laki $(57,1 \%)$ dan 15 orang perempuan $(42,9 \%)$. Pada kelompok kontrol, yaitu pasien hipertensi yang tidak menderita stroke, terdiri dari 19 orang laki-laki $(54,3 \%)$ dan 16 orang perempuan $(45,7 \%)$. Masing-masing kelompok dibagi dalam empat kelompok usia mulai dari kelompok usia 45-54 tahun hingga kelompok usia 75-84 tahun. Karakteristik menurut usia dan jenis kelamin dapat dilihat pada Tabel 1.

Menurut karakeristik tingkatan hipertensi, 
subjek penelitian dibagi menjadi prehipertensi, hipertensi stadium 1, dan hipertensi stadium 2, dapat dilihat pada Tabel 2.

Dari hasil pemeriksaan didapatkan ratarata kadar mikroalbuminuria pada kelompok kasus adalah 54,76 $(53,09) \mathrm{mg} / 24$ jam, dengan nilai minimum $2,9 \mathrm{mg} / 24$ jam dan nilai maksimum $291 \mathrm{mg} / 24$ jam. Sedangkan pada kelompok kontrol rata-rata kadar mikroalbuminuria adalah 23,56 $(23,39) \mathrm{mg} / 24$ jam, dengan nilai minimum 0,19 mg/24 jam dan nilai maksimum
$79,19 \mathrm{mg} / 24$ jam. Pada Tabel 3 dijelaskan mengenai hasil pemeriksaan mikroalbuminuria tersebut.

Model faktor penentu kejadian stroke infark aterotrombotik pada pasien hipertensi dijelaskan dalam Tabel 4.

\section{PEMBAHASAN}

Dari karakteristik demografi dilakukan pengujian

Tabel 1 Karakteristik Subjek Penelitian Menurut Jenis Kelamin dan Usia pada Kelompok Kasus dan Kelompok Kontrol

\begin{tabular}{|c|c|c|c|c|c|c|c|}
\hline \multirow[t]{2}{*}{ Karakteristik } & \multicolumn{2}{|c|}{$\begin{array}{l}\text { Kasus } \\
(n=35)\end{array}$} & \multicolumn{2}{|c|}{$\begin{array}{c}\text { Kontrol } \\
(n=35)\end{array}$} & \multicolumn{2}{|c|}{ Total } & \multirow[t]{2}{*}{ Nilai $p$} \\
\hline & $\mathrm{n}$ & $\%$ & $\mathrm{n}$ & $\%$ & $\mathrm{n}$ & $\%$ & \\
\hline Jenis Kelamin & & & & & & & $0,810^{*}$ \\
\hline Laki - laki & 20 & 57,1 & 19 & 54,3 & 39 & 55,7 & \\
\hline Perempuan & 15 & 42,9 & 16 & 45,7 & 31 & 44,3 & \\
\hline Kelompok Usia (tahun) & & & & & & & $0,264^{*}$ \\
\hline $45-54$ & 10 & 28,6 & 5 & 14,3 & 15 & 21,4 & \\
\hline $55-64$ & 8 & 22,9 & 12 & 34,3 & 20 & 28,6 & \\
\hline $65-74$ & 15 & 42,9 & 13 & 37,1 & 28 & 40,0 & \\
\hline $75-84$ & 2 & 5,7 & 5 & 14,3 & 7 & 10,0 & \\
\hline Mean (SD) & 61,83 & 8,75 & 62,90 & 9,37 & & & \\
\hline
\end{tabular}

* Chi square test

Tabel 2 Karakteristik Subjek Penelitian Menurut Tingkatan Hipertensi pada Kelompok Kasus dan Kelompok Kontrol

\begin{tabular}{|c|c|c|c|c|c|c|c|}
\hline \multirow[t]{2}{*}{ Tingkat Hipertensi } & \multicolumn{2}{|c|}{$\begin{array}{l}\text { Kasus } \\
(n=35)\end{array}$} & \multicolumn{2}{|c|}{$\begin{array}{c}\text { Kontrol } \\
(n=35)\end{array}$} & \multicolumn{2}{|c|}{ Total } & \multirow[t]{2}{*}{ Nilai $p^{*}$} \\
\hline & $n$ & $\%$ & $n$ & $\%$ & $\mathrm{n}$ & $\%$ & \\
\hline & & & & & & & 0,557 \\
\hline Stadium 2 & 1 & 2,9 & 1 & 2,9 & 2 & 2,9 & \\
\hline Stadium 1 & 31 & 88,6 & 28 & 80,0 & 59 & 84,3 & \\
\hline Prehipertensi & 3 & 8,6 & 6 & 17,1 & 9 & 12,9 & \\
\hline
\end{tabular}

* Chi Square Test

Tabel 3 Perbandingan Kadar Mikroalbuminuria Antara Kelompok Kasus dan Kelompok Kontrol

\begin{tabular}{cccc}
\hline $\begin{array}{c}\text { Kadar } \\
\text { Albumin urin }\end{array}$ & $\begin{array}{c}\text { Kasus } \\
(\mathbf{n}=35)\end{array}$ & $\begin{array}{c}\text { Kontrol } \\
(\mathbf{n}=35)\end{array}$ & Nilai $^{*}$ \\
\hline Mean $(\mathrm{SD})$ & $54,76(53,09)$ & $23,56(23,39)$ & 0,013 \\
Median & 36,48 & 11,74 & \\
Rentang & $2,9-291,00$ & $0,19-79,19$ & \\
\hline$*$ tindependent $T$ test & & &
\end{tabular}

Tabel 4 Model Faktor Penentu Kejadian Stroke Infark Aterotrombotik pada Pasien Hipertensi

\begin{tabular}{rlrrrr}
\hline Model & \multicolumn{1}{c}{ Variabel } & Koefisen $\boldsymbol{\beta}$ & Nilai $\boldsymbol{p}$ & \multicolumn{2}{c}{ OR (95\% CI) } \\
\hline Awal & \multicolumn{1}{c}{ Mikroalbuminuria } & 1,046 & 0,037 & 2,85 & $1,06-7,61$ \\
& Tingkat Hipertensi & 0,526 & 0,435 & 1,69 & $0,45-6,34$ \\
& Konstanta & $-1,165$ & & & \\
\multirow{2}{*}{ Akhir } & & & & & \\
& & & & \\
& Mikroalbuminuria & 1,068 & 0,032 & 2,91 & $1,09-7,74$ \\
& Konstanta & $-0,598$ & & & \\
\hline
\end{tabular}


secara statistik dengan Chi square test menunjukkan bahwa tidak terdapat perbedaan bermakna karakteristik subjek penelitian menurut jenis kelamin antara kelompok kasus dan kelompok kontrol dengan nilai $p=0,810$ (nilai $p>0,05$ ). Begitu pula dengan karakteristik subjek penelitian menurut kelompok usia yang juga menunjukkan tidak terdapat perbedaan secara bermakna di antara kedua kelompok dengan $p=0,264$ (nilai $p>0,05$ ). Hasil tersebut menyimpulkan bahwa kelompok kasus dan kelompok kontrol dapat dibandingkan karena secara statistik tidak terdapat perbedaan bermakna atau dengan kata lain data kedua kelompok berdasarkan karakteristik jenis kelamin dan kelompok usia adalah homogen. Pasien stroke infark aterotrombotik pada penelitian ini proporsinya lebih banyak laki-laki yaitu $57,1 \%$ dibandingkan perempuan. Data dari penelitian sebelumnya menunjukkan bahwa secara kasar untuk usia pertengahan insidensi stroke $30 \%$ lebih tinggi pada laki-laki sedang pada usia lanjut hampir tidak ada perbedaan. ${ }^{9}$ Dari segi karakteristik usia, pasien stroke infark aterotrombotik paling banyak pada rentang usia 65-74 tahun (42,9\%). Hasil ini tidak berbeda dengan yang didapat pada penelitian Framingham seperti dikutip Toole,$^{10}$ salah satu penelitian besar stroke. Hasil data demografi mengenai penderita stroke yang diteliti, pada kelompok usia 45-54 tahun insidensi stroke sebanyak 22/10.000, kelompok usia 55-64 tahun insidensinya $32 / 10.000$, dan pada kelompok usia 65-74 tahun insidensinya terbanyak yaitu 83/10.000.

Mengenai kadar mikroalbuminuria, nilai rerata kadar mikroalbuminuria pada pasien hipertensi yang menderita stroke infark aterotrombotik lebih tinggi daripada pasien hipertensi yang tidak menderita stroke. Perbedaan ini secara uji statistik menggunakan independent $T$ test mempunyai nilai yang bermakna yaitu $p=0,013$ (nilai $p \leq 0,05$ ). Dari rentang kadar albumin urin tersebut tampak bahwa pasien hipertensi yang memiliki kadar albumin urin yang tinggi menderita stroke infark aterotrombotik. Sementara pasien hipertensi yang memiliki kadar albumin urin yang tidak tinggi ataupun normal, tidak menderita stroke infark aterotrombotik. Hasil ini mendukung penelitian Tagle dkk. ${ }^{11}$ yang menemukan angka prevalensi kejadian stroke yang lebih tinggi pada pasien hipertensi nondiabetik yang memiliki mikroalbuminuria daripada pasien hipertensi yang tidak memiliki mikroalbuminuria. Bahkan pada penelitian Yuyun dkk. ${ }^{12}$ terhadap sampel urin 23.630 pasien didapatkan kejadian stroke sebanyak 246 subjek dan insidensinya meningkat sesuai dengan peningkatan albumin urin yaitu: 1,4/1.000 normoalbuminuria, 2,6/1.000 mikroalbuminuria, dan 6/1.000 makroalbuminuria. Penelitian besar lain adalah
The Shibata Study ${ }^{13}$ di Jepang dan The Copenhagen City Heart Study Group. ${ }^{14}$

Setelah dilakukan pemodelan dengan multiple logistic regression test didapatkan model terakhir yang menunjukkan bahwa mikroalbuminuria merupakan faktor penentu kejadian stroke infark aterotrombotik pada pasien hipertensi dengan nilai $p=0,032$. Berarti hipertensi saja tidak cukup kuat sebagai faktor penentu kejadian stroke infark aterotrombotik dibandingkan dengan hipertensi yang disertai mikroalbuminuria. Merujuk hipotesis penelitian sebelumnya yang menyatakan apakah mikroalbuminuria hanya merupakan petanda kerusakan vaskular ataukah merupakan faktor petanda risiko suatu penyakit, khususnya kesimpulan penelitian ini mendukung hipotesis terakhir. ${ }^{15,16}$

Berdasarkan analisis keeratan didapatkan nilai $\mathrm{OR}=2,91$ yang berarti bahwa pasien hipertensi yang memiliki mikroalbuminuria memiliki risiko stroke infark aterotrombotik 2,91 kali lebih besar dibandingkan pasien hipertensi dengan normoalbuminuria. Penelitian yang dilakukan Beamer dan Coull ${ }^{17}$ mendapatkan hasil mikroalbuminuria tiga kali lebih sering ditemukan pada pasien stroke infark dibandingkan dengan mereka yang hanya mempunyai faktor risiko stroke.

Kesimpulan: kadar mikroalbuminuria pada pasien hipertensi yang menderita stroke infark aterotrombotik lebih tinggi dibandingkan dengan pasien hipertensi yang tidak menderita stroke. Pasien hipertensi dengan mikroalbuminuria memiliki potensi terjadi stroke sebanyak 2,91 kali dibanding pasien hipertensi tanpa mikroalbuminuria dan mikroalbuminuria merupakan faktor petanda risiko terjadinya stroke infark aterotrombotik pada pasien hipertensi.

\section{DAFTAR PUSTAKA}

1. Deckert T, Feldt-Rasmussen B, Borch-Johnsen $\mathrm{K}$, Jensen $\mathrm{T}$, Kofoed-Enevoldsen A. Albuminuria reflects widespread vascular damage. Steno hypothesis. Diabetologia. 1989; 32:219-26.

2. Winocour PH, Marshal SM. Microalbuminuria; biochemistry, epidemiology, and clinical practice. Melbourne Australia: Cambridge University Press; 1998.

3. Ljungman S, Wikstrand J, Hartford M, Berglund G. Urinary albumin excretion: a predictor of risk of cardiovascular disease-a prospective 10-year follow up of middle aged nondiabetic normal and hypertensive men. Am J Hypertens. 1996;9:7708.

4. Damsgaard EM, Froland A, Jorgensen OD, Mogensen CE. Microalbuminuria as a predictor of increased mortality in elderly people. Br Med J. 1990;300:297-300.

5. Klausen FKP, Scharling $H$, Jensen $G$. New 
definition of microalbuminuria in hypertensive subjects. Hypertension. 2005;46:33-7.

6. Rossing $\mathrm{P}$, Hougaard $\mathrm{P}$, Borch-Johnsen $\mathrm{K}$, Parving $\mathrm{H}$. Predictors of mortality in hypertension, non-diabetic patients: 10-year observational follow up study. $\mathrm{Br}$ Med $\mathrm{J}$. 1996;313:779-84.

7. UPF IImu Penyakit Saraf RSHS. Data statistik pasien rawat jalan dan rawat inap. Data Statistik Juli 2006-Januari 2007.

8. Anderson CS, Jamrozik KD, Burvill PW. Ascertaining the true incidence of stroke: experience from Perth Community Stroke Study, 1989-1990. Med J Aust. 1993;158:80-4.

9. Caplan LR. Stroke a clinical approach. Edisi ke-2. USA: Butterworth-Heinemann; 1993.

10. Toole JF. Cerebrovascular disorders. Edisi ke-3. New York: Press Book Ltd; 1984.

11. Tagle R, Acevedo M, Vidt DG. Microalbuminuria: is it a valid predictor of cardiovascular risk? Cleveland Clinic J Med. 2003;70:225-61.

12. Yuyun MF, Khaw KT, Luben R, Welch A, Bingham
S, Day NE, dkk. Microalbuminuria and stroke in a british population: the European prospective investigation into cancer in Norfolk (EPICNorfolk) population study. J Intern Med. 2004;255(2):247-56.

13. Nakayama T, Date C, Yokoyama T. A 15. 5-year follow-up study of stroke in a Japanese provincial city. The Shibata Study. Stroke. 1997;28:45-52.

14. Jensen JS, Feldt-Rasmussen B, The Copenhagen City Heart Study Group. Urinary albumin excretion in a population based sample of 1011 middle aged non-diabetic subjects. Scand J Clin Lab Invest. 2005;53:867-72.

15. Bandera E, Botteri M, Minelli C, Sutton A, Abrams KR, Latronico N. Cerebral blood flow threshold of ischemic penumbra and infarct core in acute ischemic stroke. Stroke. 2006;37:1334-9.

16. Aminoff MJ. Neurology and general medicine. Edisi ke-3. New York. Churchill-Livingstone; 2005 .

17. Beamer N, Coull MM. Microalbuminuria in ischaemic stroke. Arch Neurol. 1999;56:6999 702. 